does the reverse calculation of area from the particle size measurements by the electron microscope. Accordingly, these two methods supplement rather than compete with each other. Each is superior to the other for certain purposes. Statements such as those made by Weigand ${ }^{24}$ and by Weigand and Ladd ${ }^{25}$ to the effect that the electron microscope is the only means of obtaining reliable surface areas are erroneous, as would be any statements that might be made relative to the superiority of the adsorption method over the electron microscope for obtaining particle size of finely divided substances.

${ }^{24}$ Wiegand, India Rubber World 105, No. 3, 270 ; Can. Chem. Process Ind. 25, 579 (1941).

${ }^{25}$ Wiegand and Ladd, Rubber Age 50, 431 (1942).

\section{ACKNOWLEDGMENT}

It is a pleasure to express our appreciation to the Godfrey L. Cabot Company for financing this research, to Dr. Walter Smith of that company for his many helpful suggestions and for arranging to have electron microscope pictures made on the same samples on which we measured the nitrogen adsorption, and to Dr. C. E. Hall of the Massachusetts Institute of Technology for furnishing the electron microscope photographs together with a critical discussion of the technique he used in mounting the samples and taking the electron microscope photographs. We also appreciate being able to include some unpublished electron microscope results obtained by the B. F. Goodrich Company. ${ }^{21}$

\title{
The Visco-Elastic Behavior of a Highly Plasticized Nitrocellulose in Compression under Constant Load*
}

\author{
George I. Doyle and Richard M. BadGer \\ Gates and Crellin Laboratories of Chemistry, California Institute of Technology, Pasadena, California**
}

(Received September 12, 1947)

\begin{abstract}
The behavior of a highly plasticized nitrocellulose in compression under constant load has been investigated over a rather wide range of load and temperature. The load dependence appears to require the assumption of non-Newtonian viscosity. Though the observations are not quantitatively accounted for by the Tobolsky-Eyring model, the load and temperature dependence of the rate of compression appear to have some relation to the predictions of these authors.
\end{abstract}

\section{INTRODUCTION}

$\mathrm{T}$ HE investigation here reported was a part of a program of investigation of the mechanical properties of smokeless powders recently conducted in this laboratory under a contract with the Bureau of Ordnance. This work included the study of plasticized materials in compression under constant load, and in large part consisted in the comparison of different materials. It was found desirable, however, to study at least one material under a rather wide variety of conditions of load and temperature. We believe the results obtained may be of general interest because of their relation to recently developed theories of visco-elastic behavior, and because the highly

* This paper is based on work done for the Bureau of Ordnance under contract NOrd-9652 with the California Institute of Technology.

** Contribution No. 1143 plasticized material studied is rather different from the materials on which somewhat similar studies have been reported.

\section{MATERIAL STUDIED}

The material studied was essentially a double base smokeless powder prepared by a solventless process. It contained $\mathbf{5 4 . 5}$ percent nitrocellulose and 43 percent nitroglycerine, the major plasticizing agent. The remainder of the material comprised stabilizer and inorganic materials in small amounts. The nitrocellulose was prepared from cotton linters and had a nitrogen content of about 12.6 percent. Its intrinsic viscosity in acetone solution was about 2.84 , corresponding to a weight average degree of polymerization of about $390 .^{1}$

\footnotetext{
${ }^{1}$ See Blaker, Badger, and Noyes, J. Phys. and Coll. Chem. 51, 574 (1947).
} 


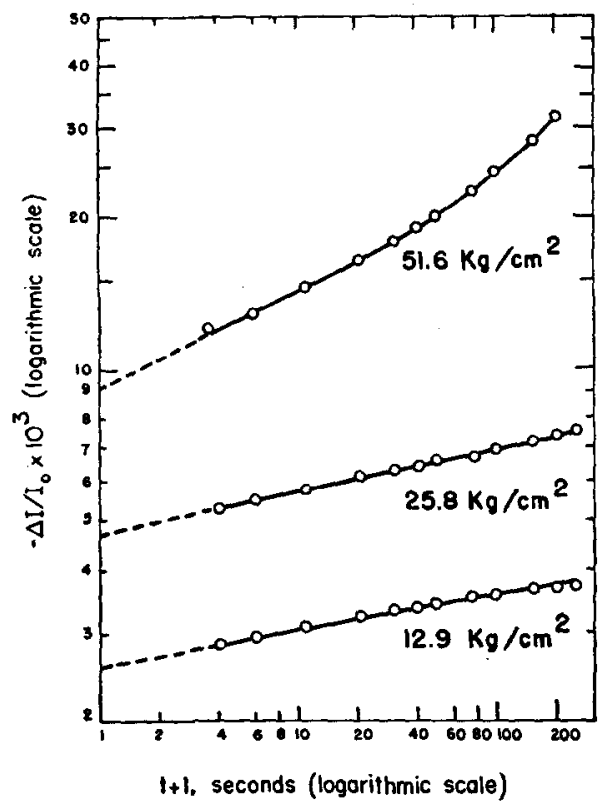

FIG. 1. Compression measurements at $20^{\circ} \mathrm{C}$.

\section{PREPARATION OF SPECIMENS}

The material was extruded in $\frac{1}{4}$-inch strands which were annealed at about $60^{\circ} \mathrm{C}$, while held in "V" grooves to produce straight specimens without strain. These were then aged for three months in stoppered tubes at room temperature. The test specimens, $0.35-0.40$ inch in length, were then cut and were stored in an air thermostat at $20^{\circ}$ and 50 percent relative humidity for five days. Before use, the ends of the specimens were made plane and parallel by dressing with fine emery paper, with the use of a jig. Considerable practice is required to do this satisfactorily. In our early work we were greatly troubled by "end effects" due to the failure of the specimens to seat properly on the anvils. In the studies here described this was almost entirely eliminated by exercising the greatest care.

The specimens to be used in a given series of measurements were stored in cylindrical, stoppered cavities in a massive brass block in which they fitted loosely. In this block they were brought to the temperature of the measurement. Temperature equilibration was found to be rapid, and when brought to any given temperature the specimens rapidly came to a steady state which did not alter during the course of several hours.

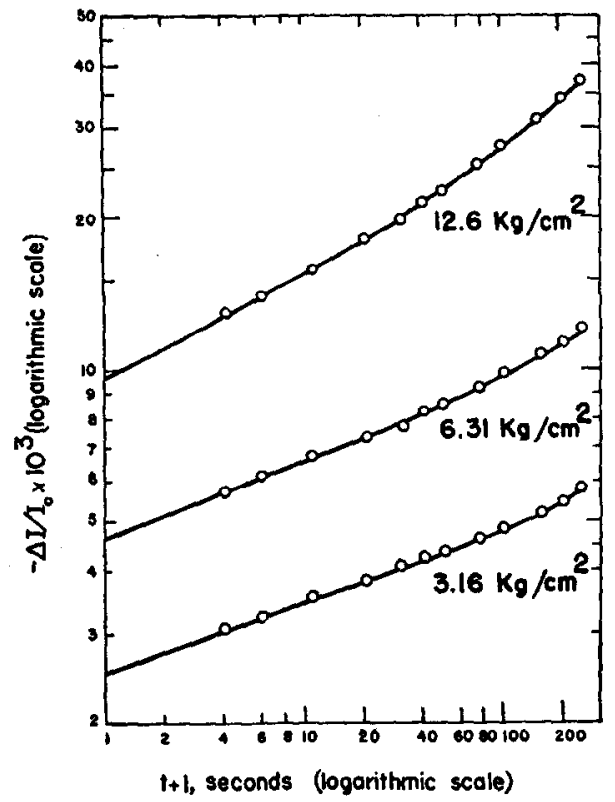

FIG. 2. Compression measurements at $50^{\circ} \mathrm{C}$.

\section{APPARATUS}

The apparatus used was a specially designed instrument which could be used either for hardness tests or for compression measurements. In certain respects it resembled conventional hardness testers but differed from them in the greater range of compressions which could be measured and in the greater choice of loads which could be employed. When used for compression measurements, the instrument was provided with two circular anvils. The surfaces between which the specimen was placed were plane parallel to within 0.0002 inch. The upper anvil was fixed during an experiment. The lower one terminated in a plunger moving in a bearing and rested on one end of a balance arm. The relative motion of the two anvils was measured with a dial indicator reading 0.0001 inch per scale division. The load was applied to the specimen by hanging weights from either of two points on the longer end of the balance arm. Precision ball bearings were used, rather than knife edges, for all balance bearings. A somewhat complicated hydraulic device permitted weights to be applied or removed almost without shock at definite times.

The anvils of the compression balance were enclosed in an air thermostat in which a rapid circulation of air at 50 percent relative humidity 
was provided. The temperature was kept constant within $0.5^{\circ} \mathrm{C}$. Thermocouples were located at various points of the instrument to permit checking the uniformity of temperature and to monitor the adjustment of a heater and water jackets which controlled the flow of heat through the metal of the balance to the anvils in the thermostat.

\section{EXPERIMENTAL PROCEDURE}

Compression measurements were made at 20 , 30,40 , and $50^{\circ} \mathrm{C}$, with three different loads in each case which covered a range of four to one. At $25^{\circ}$ four loads were used. In order to keep the compression within reasonable limits the loads employed had to be decreased at the higher temperatures, but they were so chosen that there was some overlapping of the ranges covered at two successive temperatures.

As mentioned above, the test specimens were approximately $\frac{1}{4}$ inch in diameter and $\frac{3}{8}$ inch in length. The diameter was determined by the material available, but considerable preliminary experimentation was done before the length chosen was found to offer the best compromise between two opposing difficulties. It was our purpose to study, so far as possible, the intrinsic properties of the plastic material rather than behavior largely conditioned by the shape of the specimens. Longer specimens exhibited unsatisfactory behavior under compression, which might perhaps be described as slender column failure although the ratio of length to cross section was much less than that at which such failure occurs with non-plastic materials. The compression of much shorter specimens could not be measured with adequate accuracy, and "end effects" were more serious.

When the compression of a specimen exceeded a few percent of its length, its form became noticeably "barrel shaped." The compressions studied were limited to the range in which this effect was not serious, though its consequences may have been entirely negligible.

Except at $25^{\circ}$ all measurements were made on three specimens and the results reported are average values. To avoid uncertainties due to possible variability of composition the same specimens were used throughout at any given temperature. The measurements were made in the order of increasing load to minimize the effects of previous strain history. At least one-half hour was allowed for recovery between successive measurements on the same piece. Recovery was within $0.0002-0.0005$ inch of the original length, except at the highest load and temperature where it was within 0.0008 inch. During the entire course of the measurements any permanent deformation of the specimens was so small as to be negligible.

The compression was followed by visual observation of the dial indicator. The first compression recorded was three seconds after the application of the load. Subsequent measurements were taken at suitable intervals, but terminated at 250 seconds.

\section{EXPERIMENTAL RESULTS}

Figures 1 and 2 show typical results of the compression measurements. They present the averages of three sets of measurements at $20^{\circ}$ and at $50^{\circ} \mathrm{C}$, respectively. Within the range of temperatures and loads investigated the relation between the fractional decrease in length and the time $t$ (in seconds) is adequately represented by the equation

$$
\log \left(-\Delta l / l_{0}\right)=m \log \left(\tau+t+\alpha t^{3}\right)+\log b .
$$

The observations would have to be extended to considerably shorter times to evaluate the constant $\tau$ with any accuracy, but to secure a good fit with the existing data during the early stages

Table I. Constants of Eq. (1).

\begin{tabular}{|c|c|c|c|c|c|}
\hline Temp. & $\begin{array}{c}\text { Stress } \\
\mathrm{kg} / \mathrm{cm}^{2}\end{array}$ & $m$ & $\begin{array}{l}\text { Inst. fract. } \\
\text { comp. } b\end{array}$ & $\alpha \times 10^{5}$ & $Y_{0}\left(\underset{\times 10^{-3}}{\left.\mathrm{~kg} / \mathrm{cm}^{2}\right)}\right.$ \\
\hline $20^{\circ}$ & $\begin{array}{l}12.9 \\
25.8 \\
51.6\end{array}$ & $\begin{array}{l}0.0696 \\
0.0855 \\
0.192\end{array}$ & $\begin{array}{l}0.00258 \\
0.00468 \\
0.00910\end{array}$ & $\begin{array}{l}0.0 \\
0.0 \\
6.4\end{array}$ & 5.9 \\
\hline 25 & $\begin{array}{l}7.67 \\
12.7 \\
19.0 \\
25.6\end{array}$ & $\begin{array}{l}0.065 \\
0.066 \\
0.072 \\
0.096\end{array}$ & $\begin{array}{l}0.00179 \\
0.00278 \\
0.00401 \\
0.00508\end{array}$ & $\begin{array}{l}0.0 \\
0.0 \\
0.0 \\
0.0\end{array}$ & 5.2 \\
\hline 30 & $\begin{array}{l}7.67 \\
19.2 \\
32.0\end{array}$ & $\begin{array}{l}0.0734 \\
0.0952 \\
0.171\end{array}$ & $\begin{array}{l}0.00232 \\
0.00520 \\
0.00851\end{array}$ & $\begin{array}{l}0.0 \\
2.4 \\
6.5\end{array}$ & 3.9 \\
\hline 40 & $\begin{array}{l}3.79 \\
7.57 \\
18.9\end{array}$ & $\begin{array}{l}0.0937 \\
0.105 \\
0.167\end{array}$ & $\begin{array}{l}0.00252 \\
0.00432 \\
0.0104\end{array}$ & $\begin{array}{l}6.0(?) \\
2.8 \\
5.8\end{array}$ & 1.9 \\
\hline 50 & $\begin{array}{c}3.16 \\
6.31 \\
12.6\end{array}$ & $\begin{array}{l}0.134 \\
0.150 \\
0.208\end{array}$ & $\begin{array}{l}0.00253 \\
0.00466 \\
0.0096\end{array}$ & $\begin{array}{l}3.2 \\
2.6 \\
3.8\end{array}$ & 1.3 \\
\hline
\end{tabular}




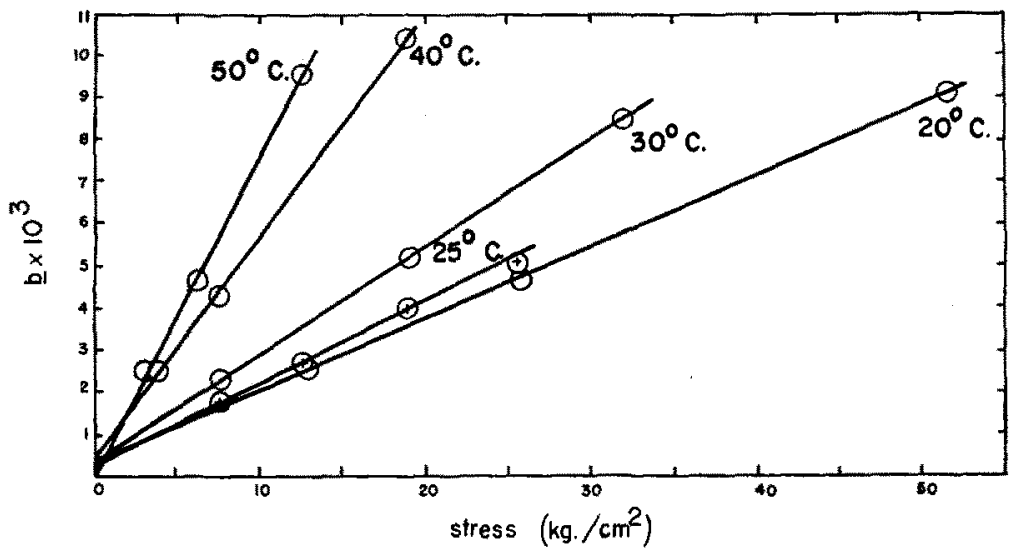

FIG. 3. Dependence of the constant $b$ on stress at various temperatures.

of compression it seems necessary to give this constant a value different from zero. In plotting the data we have arbitrarily set $\tau=1$ in all cases, and, as may be seen by reference to the figures, the fit is within the probable error. At moderate loads and temperatures the plots of $\log \left(-\Delta l / l_{0}\right)$ versus $\log (t+1)$ are straight lines within the time interval investigated. At higher loads and temperatures the plots show upward curvature which may be due in part to the deviation from cylindrical shape of the specimens when these are considerably compressed. This curvature may be taken into account in several ways. We have chosen to do so by the term in $t^{3}$ in Eq. (1).

Values of the constants $m, \alpha$, and $b$ fitting the

TABLE II. Fit of compression measurements with relation: $m F / A=a \sinh (c F / A)$.

\begin{tabular}{|c|c|c|c|c|c|c|}
\hline Temp. & $\left(\mathrm{kg} / \mathrm{cm}^{2}\right)$ & $\left(\mathrm{cm}^{2 / / \mathrm{kg}}\right)$ & $\begin{array}{c}\text { Stress, } \\
F / A \\
\left(\mathrm{~kg} / \mathrm{cm}^{2}\right)\end{array}$ & $\stackrel{m}{\text { (observed) }}$ & $\begin{array}{l}\text { m (calc. } \\
\text { from } \\
\text { Eq. }(4))\end{array}$ & $\begin{array}{l}\text { Devia- } \\
\text { tion of } \\
\text { calcu- } \\
\text { lated } m \\
\text { percent }\end{array}$ \\
\hline 20 & 1.09 & 0.0565 & $\begin{array}{l}12.9 \\
25.8 \\
51.6\end{array}$ & $\begin{array}{l}0.0696 \\
0.0855 \\
0.192\end{array}$ & $\begin{array}{l}0.0673 \\
0.0860 \\
0.195\end{array}$ & $\begin{array}{l}-3.3 \\
+0.6 \\
+0.16\end{array}$ \\
\hline 25 & 0.93 & 0.0643 & $\begin{array}{c}7.67 \\
12.7 \\
19,0 \\
25.6\end{array}$ & $\begin{array}{l}0.065 \\
0.066 \\
0.072 \\
0.096\end{array}$ & $\begin{array}{l}0.062 \\
0.067 \\
0.076 \\
0.091\end{array}$ & $\begin{array}{r}-4.6 \\
+1.5 \\
+5.6 \\
-5.2\end{array}$ \\
\hline 30 & 0.865 & 0.0790 & $\begin{array}{c}7.67 \\
19.2 \\
32.0\end{array}$ & $\begin{array}{l}0.0734 \\
0.0952 \\
0.171\end{array}$ & $\begin{array}{l}0.0726 \\
0.0979 \\
0.168\end{array}$ & $\begin{array}{r}-1.1 \\
+2.8 \\
-1.8\end{array}$ \\
\hline 40 & 0.92 & 0.103 & $\begin{array}{r}3.79 \\
7.57 \\
18.9\end{array}$ & $\begin{array}{l}0.094 \\
0.105 \\
0.167\end{array}$ & $\begin{array}{l}0.097 \\
0.104 \\
0.168\end{array}$ & $\begin{array}{l}+3.2 \\
+1.0 \\
+0.6\end{array}$ \\
\hline 50 & 0.90 & 0.144 & $\begin{array}{l}3.16 \\
6.31 \\
12.6\end{array}$ & $\begin{array}{l}0.134 \\
0.150 \\
0.208\end{array}$ & $\begin{array}{l}0.133 \\
0.143 \\
0.214\end{array}$ & $\begin{array}{l}-0.7 \\
-4.7 \\
+2.9\end{array}$ \\
\hline
\end{tabular}

data at the various loads and temperatures are given in Table $I$.

In giving a purely formal interpretation of Eq. (1), the constant $b$ may be regarded as an "instantaneous" fractional compression which occurs immediately upon the application of the load. At any given temperature $b$ increases linearly with the load, well within experimental error, as may be seen in Fig. 3. The failure of some of the plots to pass through the origin is believed to result from residual "end effects" previously mentioned. In previous work it was found that improvement in the technique of preparing specimens always reduced the zeroload intercept of these plots. From the slopes of the straight lines of Fig. 3 one may calculate a fictitious "instantaneous Young's modulus" by the relation:

$$
Y_{0}\left(\mathrm{~kg} / \mathrm{cm}^{2}\right)=1 / \frac{d b}{d(F / A)},
$$

where $F$ is the load in kilograms, and $A$ the crosssectional area of the specimen in square $\mathrm{cm}$.

The constants $b$ or $Y_{0}$ have a simple dependence on temperature which is very well expressed by the relation:

$$
Y_{0}\left(\mathrm{~kg} / \mathrm{cm}^{2}\right)=1.34_{8} \exp (-10,300 / 1.986 T)
$$

where $T$ is the absolute temperature.

The constant $m$ of our empirical equation shows a rather complicated dependence on load and temperature. The available data are not adequate to determine uniquely this relationship, but the load dependence is represented, within 
experimental error, by the equation :

$$
m F / A=a \sinh (c F / A) .
$$

With the available data considerable latitude is permitted in the choice of the constants $a$ and $c$, but in Table II pairs of constants are given at each temperature which represent the data with the accuracy shown in the final column of the table.

In the range investigated, the constant $a$ does not change greatly with temperature. The temperature dependence of $c$ is well represented by the relation:

$$
c=\frac{1}{T} \exp \left(\frac{-6370}{1.986 T}+14.30\right),
$$

as may be seen in Fig. 4.

\section{DISCUSSION OF THE RESULTS}

At any one load and temperature the behavior of our material, as represented in Eq. (1), could doubtless be simulated by a model consisting of spring and dashpot elements having an appropriate distribution of relaxation times $;{ }^{2}$ we doubt, however, that the dependence of the rate of compression on load, which we have observed, could be accounted for in terms of a classical model without some rather arbitrary assumptions. This behavior appears to offer support for the nonNewtonian viscosity which has been assumed by Tobolsky and Eyring in their recent discussion of visco-elastic behavior. ${ }^{3}$

These authors have discussed a simple model, which, under compression during times which are not too long, should show behavior represented by an equation of the form :

$$
-\Delta l=\beta[\ln (t+\delta)-\ln \delta],
$$

where $\beta$ and $\delta$ are constants at a given load and temperature. Equation (5) is inadequate to fit our data over more than very short time intervals. This is to be expected, since the model on which it is based comprises a single dashpot element. A further elaboration of this model along the lines

\footnotetext{
2 See, for example, R. Simha, J. Phys. Chem. 47, 348 (1943).

${ }^{3}$ A. Tobolsky and H. Eyring, J. Chem. Phys. 11, 125 (1943).
}

already followed with classical models could probably be made to give satisfactory agreement with experiment, though the solution of the equations of motion presents mathematical difficulties.

At the present time it does not appear possible to attribute any very definite significance to the constants of our empirical equation, but we may point out a relation between our observations and the behavior of the Tobolsky-Eyring model which may have some significance. From Eq. (1), the rate of fractional compression at any time is given by:

$$
\frac{d\left(-\Delta l / l_{0}\right)}{d t}=m b(\tau+t)^{m-1},
$$

if we ignore the term in $t^{3}$. At a time near the beginning of the compression, namely, when $(\tau+t)=1$, this rate is equal to $m b$ or $m F / A Y_{0}$. The observed load dependence of this quantity is given above in Eq. (4). It is precisely the same as the load dependence of the initial rate of compression of the model of Eyring and Tobolsky, as

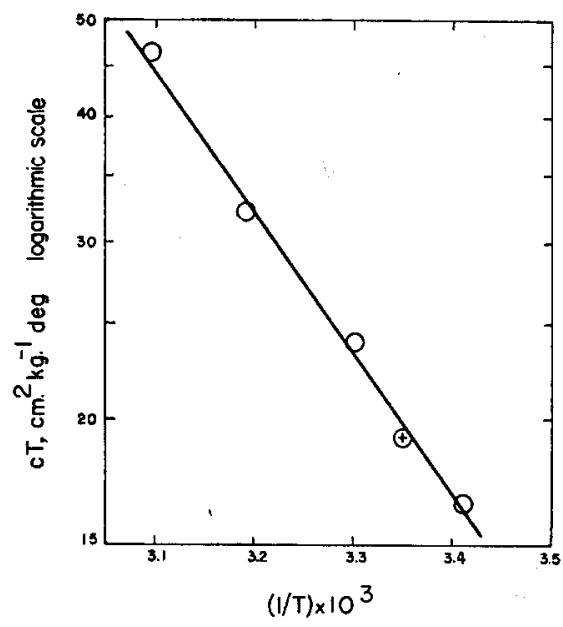

FIG. 4. Dependence of $\log c T$ on $1 / T$.

may be seen by reference to their Eqs. $(6){ }^{3}$ The temperature dependence of $m b$ or $m F / A Y_{0}$ is also very similar to that anticipated by these authors for their initial rate. To what extent this correlation has physical significance or is accidental can scarcely be decided until a more elaborate model has been discussed in detail. 